Supporting Information for

\title{
Cadmium(II) removal by mackinawite under anoxic conditions
}

Sung Pil Hyun ${ }^{1,2 *}$, Bo-a Kim¹, Sangbo Son ${ }^{3}$, Kideok D. Kwon ${ }^{3}$, Eungyeong Kim ${ }^{1}$, Kim F. Hayes $^{2}$

${ }^{1}$ Korea Institute of Geoscience and Mineral Resources, Daejeon 34132, Republic of Korea; ${ }^{2}$ University of Michigan, Ann Arbor, Michigan 48109, USA;

${ }^{3}$ Kangwon National University, Gangwon 24341, Republic of Korea;

*Corresponding author: Sung Pil Hyun

Center for HLW Geological Disposal

Korea Institute of Geoscience and Mineral Resources

124 Gwahak-ro, Yuseong-gu

Daejeon 34132, Republic of Korea

+1-82-42-868-3315

sphyun@kigam.re.kr 


\section{Materials and Methods}

\section{Preliminary experiments}

Prior to the Cd uptake experiments, we carried out acid titration of the FeS suspensions to determine the necessary amounts of acid to achieve the desired $\mathrm{pH}$ values. The titration showed that the background electrolyte did not influence the acid amounts. It also showed that the $\mathrm{Cd}$ addition did not significantly change the $\mathrm{pH}$ values. We also performed a $\mathrm{Cd}^{2+}$ reaction with dissolved HS- We observed that $\mathrm{Cd}^{2+}$ removal from the solution was almost complete. We characterized the solid phase formed from the homogeneous nucleation to confirm that $\mathrm{CdS}$ precipitation is responsible for the aqueous $\mathrm{Cd}^{2+}$ removal from the solution. We further used the $\mathrm{CdS}$ formed from the homogeneous precipitation as reference material in characterizing the solid phase reaction products in the reaction of $\mathrm{Cd}^{2+}$ with $\mathrm{FeS}$.

Unlike the homogeneous reaction with aqueous sulfide, the $\mathrm{Cd}$-induced FeS dissolution due to the difference in the solubility of FeS and $\mathrm{CdS}$ does not involve proton (Reaction (2) in the text) and hence did not cause a noticeable shift in the titration curve under the experimental conditions. The net proton balance of the overall reaction is zero:

$$
\begin{aligned}
& \mathrm{FeS}(\mathrm{s})+\mathrm{H}^{+}=\mathrm{Fe}^{2+}+\mathrm{HS}^{-} \\
& \mathrm{Cd}^{2+}+\mathrm{HS}^{-}=\mathrm{CdS}+\mathrm{H}^{+}
\end{aligned}
$$

The titrations and the homogeneous reactions with dissolved sulfide constitute the control experiments based on which the $\mathrm{Cd}(\mathrm{II})$ reaction mechanisms with FeS were interpreted.

\section{$X$-ray diffraction}

We prepared the samples for X-ray diffraction in an anaerobic chamber $\left(\mathrm{N}_{2}\right.$ atmosphere with $\sim 3 \% \mathrm{H}_{2}$ ). First, we prepared a $0.1 \mathrm{M} \mathrm{Cd}$ stock solution by dissolving $\mathrm{CdCl}_{2(\mathrm{~s})}(\mathrm{ACS}$ grade, Sigma-Aldrich) in anoxic deionized water. Then we mixed $1 \mathrm{~g}$ of mackinawite powder with 100 $\mathrm{mL}$ of $0.1 \mathrm{M} \mathrm{NaCl}$ background electrolyte solution or $0.5 \mathrm{~g}$ of mackinawite with $50 \mathrm{~mL}$ of the electrolyte solution to obtain 1 or $10 \mathrm{~g} / \mathrm{L}$ mackinawite suspension. Next, we transferred $50 \mathrm{~mL}$ of 
the mackinawite suspensions to $50 \mathrm{~mL}$ conical tubes. After that, we spiked appropriate volumes of the $\mathrm{Cd}$ stock to the mackinawite suspensions to get 1 or $10 \mathrm{mM}$ initial $\mathrm{Cd}$ concentration. Next, we adjusted the $\mathrm{pH}$ of each conical tube using a $1 \mathrm{~N} \mathrm{HCl}$ or $\mathrm{NaOH}$ solution (volumetric standard, Sigma-Alrich). Then, we let the reaction occur while continuously shaking the samples in the conical tubes at room temperature using a tube rotator (FinePCR AG). After $24 \mathrm{~h}$ of reaction, we measured the $\mathrm{pH}$ of each mixture using a $\mathrm{pH}$ meter and a probe (Thermo-Orion Versa Star meter and Thermo-Orion semi-micro combination electrode) in the anaerobic chamber. Finally, we filtered the solid particles using $0.2 \mu \mathrm{m}$ membrane filters (Advantec ${ }^{\circledR}$ ) and vacuum-dried them in the anaerobic chamber. We also transferred the suspensions to glass slides and vacuum-dried them without filtering. We measured the diffraction patterns of the Cd-loaded mackinawite samples with an X-ray diffractometer (Philips X'Pert MPD), using $\mathrm{Cu} K \alpha$ radiation as the $\mathrm{X}$-ray source in the range of 2 -theta between $3^{\circ}$ and $75^{\circ}$ with $0.01^{\circ} 2$ theta step increments. We performed search and match of the XRD peaks on the obtained XRD patterns using Phillips/X'Pert Graphics \& Identify.

X-ray absorption spectroscopy

The Cd-loaded FeS samples were freshly prepared under different $\mathrm{pH}$ conditions just before the XAS data collection. This was accomplished by adding FeS powder to varying $\mathrm{NaCl}$ (Fisher) background electrolyte solution concentrations for a final FeS concentration of $1 \mathrm{~g} / \mathrm{L}$ or $10 \mathrm{~g} / \mathrm{L}$. Appropriate amounts of the $\mathrm{Cd}$ stock solution of $\mathrm{CdCl}_{2}(s)$ salt (Aldrich) were then spiked into the FeS suspensions to obtain desired initial $\mathrm{Cd}$ concentrations. The $\mathrm{pH}$ was adjusted using $0.1 \mathrm{M}$ or $1 \mathrm{M} \mathrm{HCl}$ or $\mathrm{NaOH}$ (Fisher). The final $\mathrm{pH}$ of each sample was measured after two days of reaction on the end-over-end rotator at room temperature. Finally, three types of samples 
were prepared for XAS data collection: (a) suspension, (b) paste after centrifugation and filtration, and (c) powder after freeze-drying of the paste. All samples were stored in tightly sealed septa vials to prevent exposure to atmospheric oxygen and then shipped to the beam line. XAS data reduction and analysis were performed using SIXPack..$^{20}$ For Ge detector spectra, suitable channels were selected to optimize the output signal. Energy position calibration was conducted using the simultaneously measured $\mathrm{Cd}$ metal spectrum followed by averaging of the multiple scan signals. Next, the background was removed from the averaged signal using linear fits below the edge and spline fits above it. EXAFS analysis on the background subtracted, normalized EXAFS data was performed using the FEFF EXAFS fitting sub-program of SIXPack with a non-linear least squares fitting algorithm. Amplitude and phase function for each backscattering path were obtained from theoretical calculations using FEFF8.10 code. To verify the validity of the atomic shell-based approach, the EXAFS data of the model compound CdS (greenockite) of known local structure from the XAFS Spectra Library was analyzed (cars.uchicago.edu/xaslib/spectrum/665-667). The structural information extracted from the EXAFS analysis was then compared with the reported one. The model compound analysis indicated that the one atomic shell approach was optimal for modeling the nearest neighbors around the central $\mathrm{Cd}$ when considering the trade-off between the number of the fitting parameters and the corresponding goodness of the fit value. Virtually the same goodness of fit was obtained using a weighted average of the two slightly different subshells of greenockite constituting the nearest neighbors atomic shell. Finally, the structural parameters from the EXAFS data of the Cd samples with unknown structures were extracted using the same one-shell approach found optimal from the model compound data analysis. 


\section{Results}

\section{Batch Cd removal}

Cd removal and dissolved $\mathrm{Fe}$ and $\mathrm{S}$ concentrations in $0.05 \mathrm{M} \mathrm{NaCl}$ background electrolyte were almost identical to the $0.1 \mathrm{M} \mathrm{NaCl}$ solution results, viz., nearly complete $\mathrm{Cd}$ removal over the whole $\mathrm{pH}$ range with no apparent sorption $\mathrm{pH}$ edge, with some dissolved $\mathrm{Fe}(\mathrm{II})$ and $\mathrm{S}(-\mathrm{II})$ appearing at $\mathrm{pH}$ lower than 5 (Fig. S1). In contrast, the solution chemistry of Cd(II) reacted FeS in $0.01 \mathrm{M} \mathrm{NaCl}$ background electrolyte solution was different from that in the more concentrated salt solutions (Fig. S2). Dissolved Fe was detected not only at $\mathrm{pH}$ below 5, but also at $\mathrm{pH}$ higher than 6 (Fig. S2). This is inconsistent with the $\mathrm{pH}$ dependency of FeS solubility, which as noted previously, dramatically decreases as the $\mathrm{pH}$ increases above 6. The different $\mathrm{Cd}$ removal and dissolved ion behavior in $0.01 \mathrm{M} \mathrm{NaCl}$ solution is likely due to colloidal particles' contribution. Filtering the $\mathrm{Cd}$ loaded $\mathrm{FeS}$ particles from $0.01 \mathrm{M} \mathrm{NaCl}$ suspensions through the $0.20 \mu \mathrm{m}$ filters was incomplete as evidenced by the dark color of the filtered solution indicating sub-micrometer sized FeS particles passed through these filters (Fig. S2e). After re-filtration with $0.015 \mu \mathrm{m}$ filters, no dissolved Fe or Cd was detected (Fig. S2b). This observation confirms that the measurable $\mathrm{Cd}$ in solutions filtered with $0.20 \mu \mathrm{m}$ filters at $\mathrm{pH}$ higher than 6 in the $0.01 \mathrm{M} \mathrm{NaCl}$ suspensions are attributed to $\mathrm{Cd}$ associated with colloidal FeS particles that were not retained by the $0.2 \mu \mathrm{m}$ filter.

Previous studies show nano-scale particles form when synthesizing FeS following the same procedures used in this study (Gallegos et al., 2007; Jeong et al., 2008; Hyun and Hayes, 2009; Hyun et al., 2012). In lower ionic strength condition of the $0.01 \mathrm{M} \mathrm{NaCl}$, aggregation of the individual colloidal FeS particles is not as effective as in higher ionic strength conditions, which 
led to incomplete filtration with the $0.20 \mu \mathrm{m}$ filters. Given the observation of no measurable $\mathrm{Cd}$ in the solution samples re-filtered with $0.015 \mu \mathrm{m}$ filters, it indicates the complete association of $\mathrm{Cd}$ with the solid phases including the colloidal fraction in $0.01 \mathrm{NaCl}$ solution even though complete filtration is not accomplished with the $0.20 \mu \mathrm{m}$ filters. This conclusion suggests that $\mathrm{Cd}$ removal by FeS likely follows the same mechanism regardless of the ionic strength conditions. Furthermore, it suggests that a significant fraction of $\mathrm{Cd}$ is colloid-bound $\mathrm{Cd}$ when reacted with FeS, even though it is observed only under the lower ionic strength condition. Outer-sphere metal surface complex formation may also have a distinct ionic strength dependency (Hayes and Leckie, 1987). However, increasing ionic strength typically results in less adsorption and a broadening of the sorption $\mathrm{pH}$ edge, neither of which was observed in this study. Hence, the differences in $\mathrm{Cd}$ removal as a function of ionic strength and $\mathrm{pH}$ in this study are explained by $\mathrm{Cd}$ association with colloidal $\mathrm{FeS}$ or colloidal CdS formation combined with the nearly quantitative $\mathrm{Cd}$ removal over a wide range in $\mathrm{pH}$, initial $\mathrm{FeS}$ and $\mathrm{Cd}$, and $\mathrm{NaCl}$ concentrations.

X-ray diffraction

Fig. S3 shows the X-ray diffraction (XRD) patterns of the Cd-loaded mackinawite samples prepared under the different geochemical conditions. The patterns are very noisy in general, and the peaks are not clear (Fig. S3). We observe some of the greenockite-like or hawleyite-like peaks, but they are far from complete patterns. The XRD suggests that the cadmium sulfides formed are poorly crystalline in nature and nano-scale in size. We cannot, however, confirm which of the two polymorphs of $\mathrm{CdS}$ precipitated under the different geochemical conditions based solely on the XRD patterns. Moreover, many of hawleyite's 
signature peaks overlap with greenockite's (Deore and Navrotsky, 2006). XRD does not tell whether a solid-solution resulting from $\mathrm{Cd}$ substituting for Fe forms, either. We, therefore, conclude that it is likely that $\mathrm{Cd}$ forms poorly crystalline cadmium sulfide phases by reaction with mackinawite under the experimental conditions studied. X-ray diffraction did not give a definite answer to the $\mathrm{Cd}$ removal mechanism by mackinawite, i.e., simple adsorption, solidsolution formation, and discrete sulfide formation.

\section{Transmission electron microscopy}

Figure S4 shows the Cd enriched parts observed by STEM and corresponding characteristic X-ray maps. Figure S5a shows the transmission electron images of the typical CdS nano-particles along with the darker, larger aggregates formed from the reaction of $\mathrm{Cd}$ (II) with FeS. Figure $\mathrm{S} 5 \mathrm{~b}$ is the corresponding secondary electron image of the CdS aggregates with $z$ contrast. The characteristic X-ray maps (Figure S5c for Cd and S5d for S) confirm that the aggregates are CdS. Figure S5e shows the aggregation of CdS nano-particles formed from homogeneous reaction of aqueous $\mathrm{Cd}(\mathrm{II})$ with aqueous $\mathrm{S}(-\mathrm{II})$. It is similar to the CdS aggregation observed in the reaction between $\mathrm{Cd}(\mathrm{II})$ and FeS (Figure S5a).

\section{EXASF analysis of the model compounds}

To develop a proper EXAFS data analysis strategy, we extracted the local coordination information around the central $\mathrm{Cd}$ atoms from the EXAFS data analysis on $\mathrm{Cd}$ in a model compound of known structure (Figure S6). First, we fitted the CdS (greenockite) spectrum from the XAFS Spectra Library (cars.uchicago.edu/xaslib/spectrum/665-667) using the Feff fitting 
module of SixPack (Webb, 2005), an IFEFFIT-based graphical user interface (Newville, 2001). To do this, we first averaged all three available scans and removed the background to reduce the EXAFS spectrum. Next, we performed Feff fitting using the backscattering paths obtained through Feff8.10 calculations using the Feff input files obtained from Webatoms calculations with the crystallographic data for greenockite, the hexagonal, wurtzite $(\mathrm{ZnS})$ structured polymorph of CdS(s) with the space group of $P 6_{3} m c$ (Wyckoff, 1963). Wyckoff (1963) reported that the central Cd atom in greenockite has three $\mathrm{S}$ at $2.51023 \AA$ and one $\mathrm{S}$ at $2.59836 \AA$ as the nearest neighbors, whereas $\mathrm{Xu}$ (1993) reported one $\mathrm{S}$ atom at $2.51790 \AA$ and another three $\mathrm{S}$ atoms at $2.53167 \AA$ as the nearest neighbors. It then has $6 \mathrm{Cd}$ neighbors located at $4.13353 \AA, 6$ $\mathrm{Cd}$ at $4.13480 \AA, 1 \mathrm{~S}$ at $4.15063 \AA, 3 \mathrm{~S}$ at $4.83713 \AA$, and $6 \mathrm{~S}$ at $4.88345 \AA$. Based on these crystallographic data, we conducted the fitting up to the $R$-value of $5 \AA$ while keeping the coordination numbers fixed. Although we could force our model to fit the data, the EXAFS analysis did not allow us to effectively resolve the two slightly different subshells that constitute the first shell, even with the spectrum of the well-ordered model compound measured at $10 \mathrm{~K}$. Hence we then tried to fit the data while floating the coordination number for the atomic shells. We found that the single first shell fitting with the coordination number fixed at 4 gave a surprisingly good result while at the same time keeping the fitting parameters minimal. Likewise, the fitting with a second and third shell of a single $\mathrm{Cd}$ and $\mathrm{S}$ shell with the fixed coordination number of 12 respectively gave a satisfactory result, compared to the subshell based fitting with more fitting parameters. Considering the tradeoff of the number of adjustable parameters and the corresponding goodness of the fit values, we got the final fitting result of $4 \mathrm{~S}$ at $2.526 \AA, 12 \mathrm{Cd}$ at $4.118 \AA$, and $12 \mathrm{~S}$ at $4.849 \AA$ over the $k$ range between 3 and $16.5\left(\AA^{-1}\right)$ and $R$ between 1 and 5 $(\AA)$. The first shell parameters are consistent with the "simplified" greenockite coordination 
model with $4 \mathrm{~S}$ atoms at $2.532 \AA$ or $2.528 \AA$ as the first shell for greenockite, which is the weighted average of the two subshells, for the simplicity of fitting.

The cubic (space group $\mathrm{F} \overline{4} 3 m$ ), sphalerite $(\mathrm{ZnS})$ structured hawleyite (Wyckoff, 1963) is the other possible polymorph of $\mathrm{CdS}_{(\mathrm{s})}$. Crystallographic studies reported that the central $\mathrm{Cd}$ atom in hawleyite has 4 nearest S neighbors at 2.5258 $\AA$ (Skinner, 1961) or $2.5193 \AA$ (Wyckoff, 1963). It also has $12 \mathrm{Cd}$ backscatterers at $4.12455 \AA$ and $12 \mathrm{~S}$ atoms at $4.83647 \AA$ as the nearest backscatterer shells up to $5 \AA$. The above structural parameters extracted from the EXAFS analysis of the greenockite reference spectrum, viz., $4 \mathrm{~S}$ at $2.526 \AA, 12 \mathrm{Cd}$ at $4.118 \AA$, and $12 \mathrm{~S}$ at $4.849 \AA$ are very similar to the crystallographic data for hawleyite.

From the fitting exercise, we learned that the EXAFS modeling using the structural model and backscattering paths based on either hawleyite or greenockite gave almost identical results in terms of the structural parameters as well as the corresponding goodness of the fit values. The fitting using the two $\mathrm{S}$ subshells at the slightly different distances from the central $\mathrm{Cd}$ atom in greenockite gave practically the same goodness of the fit value as the one $\mathrm{S}$ shell fitting even with the increased number of fitting parameters. Thus for simplicity of fitting, we followed the single shell approach, regarding the structural parameters obtained as the weighted average of the two subshells constituting the first atomic shell in greenockite. We then set the first shell coordination number at 4 to obtain the optimal amplitude reduction factor $S_{0}^{2}$ value of 0.7678 . On the basis of these observations, we devised the following EXAFS fitting strategy: 1) we used the weighted average of the first shell similar to the simpler hawleyite structure using 3 atomic shells in the R range between 1 and $5 \AA$; 2) we used throughout the sample analysis the amplitude reduction factor $\mathrm{S}_{0}^{2}$ of 0.7678 obtained from the model compound fitting. Hence we decided to use "CdS," rather than trying to differentiate between greenockite and hawleyite. 
The $\mathrm{Cd} K$-edge EXAFS $\chi(k)$-function as well as the corresponding Fourier transform magnitude function of $\mathrm{Cd}(\mathrm{OH})_{2(\mathrm{~s})}$ model compound have features distinct from those of $\mathrm{CdS}_{(\mathrm{s})}$. The structural parameters extracted from the EXAFS data analysis show a distinct first coordination shell. $\mathrm{Cd}$ in $\mathrm{Cd}(\mathrm{OH})_{2(\mathrm{~s})}$ has six $\mathrm{O}$ neighbors with the $\mathrm{Cd}-\mathrm{O}$ distance of $2.278 \AA$ as the nearest neighbors. It also has a distinct second shell feature in the Fourier transform magnitude function, arising from six Cd second nearest neighbors located at $3.488 \AA$ from it.

\section{Thermodynamic considerations}

The suite of the analytical techniques used in this study shows that the major mechanism of aqueous $\mathrm{Cd}(\mathrm{II})$ removal by $\mathrm{FeS}$ is via $\mathrm{CdS}$ precipitation. Typically reported solubility product $\left(K_{\mathrm{sp}}\right)$ values of $\mathrm{CdS}$ for the $\mathrm{MeS}_{(\mathrm{s})}+\mathrm{H}^{+}=\mathrm{Me}^{2+}+\mathrm{HS}^{-}$formulation are more than ten orders of magnitude less than those of FeS. For example, the $K_{\mathrm{sp}}$ values reported by Morse and Arakaki (1993) are $7.94 \times 10^{-15}$ for CdS and $2.29 \times 10^{-4}$ for FeS. For CdS, the visual MINTEQ database has the $\log K_{\mathrm{sp}}$ value of $-14.02\left(K_{\mathrm{sp}}=9.55 \times 10^{-15}\right)$. The value of $-14.36\left(K_{\mathrm{sp}}=4.37 \times 10^{-15}\right)$ was reported by Daskalakis and Helz (1992). Rickard and Luther (2007) reports the $\log K_{\mathrm{sp}}$ value of -3.5 $\left(K_{\mathrm{sp}}=3.16 \times 10^{-4}\right)$ for FeS. The value in the visual MINTEQ database is $-3.6\left(K_{\mathrm{sp}}=2.51 \times 10^{-4}\right)$. Thermodynamics hence predicts precipitation of CdS at the expense of coexisting FeS.

However, thermodynamics could not predict which of the CdS's dimorphs will precipitate. Solubility data for hawleyite are not readily available: Framson and Leckie (1978) used the same value for both minerals; Daskalakis and Helz (1992) reported that the free energies of formation for cubic (hawleyite) and hexagonal (greenockite) $\mathrm{CdS}$ are very similar to each other, suggesting that solution conditions may influence which polymorph forms. Banfield and Zhang (2001) reported that the stable phase for macroscopic CdS at room temperature and 
pressure is hawleyite, whereas Bostick et al. (2000) concluded that hawleyite is the preferred $\mathrm{CdS}$ phase under a higher surface coverage when $\mathrm{Cd}$ reacts with $\mathrm{FeS}_{2}$, with $\mathrm{Cd}$ surface concentration determining the prevalence of hawleyite or greenockite. Hawleyite is reported to be energetically metastable $\left(\Delta \mathrm{H}_{\mathrm{f}}^{0}=-147.65 \pm 4.28 \mathrm{~kJ} \mathrm{~mol}^{-1}\right)$ by about $1 \mathrm{~kJ} \mathrm{~mol}^{-1}$ in terms of formation enthalpy, compared to greenockite $\left(-148.79 \pm 4.13 \mathrm{~kJ} \mathrm{~mol}^{-1}\right)$ (Deore and Navrotsky, 2006). Parkman et al. (1999) concluded that aqueous Cd uptake by synthetic mackinawite seemed to produce a CdS phase, such as greenockite or hawleyite, based on the XANES and EXAFS analysis. Hence these previous studies have concluded the precipitation of CdS as the result of aqueous $\mathrm{Cd}(\mathrm{II})$ uptake by $\mathrm{FeS}$ without specifying between the dimorphs. 


\section{Supporting Information References}

cars.uchicago.edu/xaslib/spectrum/665-667

Banfield J.F.; Zhang H. Nanoparticles in the environment. Reviews in Mineralogy and Geochemistry 2001, 44, 1-58.

Bostick B.C.; Fendorf S.; Fendorf M. Disulfide disproportionation and CdS formation upon cadmium sorption on $\mathrm{FeS}_{2}$. Geochmi. Cosmochim. Acta 2000, 64, 247-255.

Daskalakis K.D.; Helz G.R. Solubility of CdS (greenockite) in sulfidic waters at $25^{\circ}$ C. Environ. Sci. Technol. 1992, 26, 2462-2468.

Deore, S.; Navrotsky, A. Oxide melt solution calorimetry of sulfides: Enthalpy of formation of sphalerite, galena, greenockite, and hayleyite. Am. Mineral. 2006, 92, 400-403.

Framson P. E.; Leckie J. O. Limits of Coprecipitation of Cadmium and Ferrous Sulfides. Environ. Sci. Technol. 1978, 12, 465-469

Gallegos T. J.; Hyun S. P.; Hayes K. F. Spectroscopic investigation of the uptake of arsenite from solution by synthetic FeS. Environ. Sci. Technol. 2007, 41, 7781-7786, DOI : 10.1021/es070613c.

Hayes K.F.; Leckie J.O. Modeling ionic strength effects on anion adsorption at hydrous oxide/solution interfaces. J. Colloid Interface Sci. 1987, 125, 717-726.

Hyun S.P.; Hayes K. F. Feasibility of using in situ FeS precipitation for TCE degradation. $J$. Environ. Eng. 2009, 135, 1009-1014, DOI : 10.1061/(ASCE)EE.1943-7870.0000073. 
Hyun S. P.; Davis J. A.; Sun K.; Hayes K. F. Uranium(VI) reduction by iron(II) monosulfide FeS. Environ. Sci. Technol. 2012, 46, 3369-3376, DOI : 10.1021/es203786p.

Jeong H. Y.; Lee J. H.; Hayes K. F. Characterization of synthetic nanocrystalline FeS: Crystal structure, particle size, and specific surface area. Geochim. Cosmochim. Acta 2008, 72, 493-505, DOI : 10.1016/j/gca.2007.11.008.

Morse J.W.; Arakaki T. Adsorption and coprecipitation of divalent metals with mackinawite (FeS). Geochmi. Cosmochim. Acta 1993, 57, 3635-3640.

Newville M. The IFEFFIT Tutorial, Consortium for Advanced Radiation Sources, University of Chicago, Chicago, 2001.

Parkman R. H.; Charnock J. M.; Bryan N. D.; Livens F. R.; Vaughan D. J. Reactions of copper and cadmium ions in aqueous solution with goethite, lepidocrocite, FeS, and pyrite. Am. Miner. 1999, 84, 407-419, DOI : 10.2138/am-1999-0326.

Rickard D.; Luther III G.W. Chemistry of iron sulfides. Chem. Rev. 2007, 107, 514-562.

Skinner B. J. Unit-cell edges of natural and synthetic sphalerites. Am. Mineral. 1961, 46, 13991411.

Webb S. M. SIXPack: A graphical user interface for XAS analysis using IFEFFIT. Physica Scripta 2005, T115, 1011-1014.

Wyckoff, R.W.G. Crystal Structures, Interscience Publishers, 1963, pp. 111-112.

Xu Y.- N. and Ching W. Y. (1993) Electronic, optical, and structural properties of some wurtzite crystals. Phys. Rev. B 1993, 48, 4335-4351. 


\section{Figure Captions}

Figure S1. Cd removed (\%), dissolved Fe(II) or S(-II) released $(\mu \mathrm{M})$ as a function of $\mathrm{pH}$ conditions. Initial Cd of (a) $10^{-4} \mathrm{M}$, (b) $10^{-5} \mathrm{M}$, (c) $10^{-6} \mathrm{M}$, and (d) $10^{-7} \mathrm{M} \mathrm{Cd}$ in $0.05 \mathrm{M}$ $\mathrm{NaCl}$ background electrolyte solution.

Figure S2. ; Cd removed (\%), dissolved Fe(II) or S(-II) released $(\mu \mathrm{M})$ as a function of $\mathrm{pH}$ conditions. Initial Cd of (a) $10^{-4} \mathrm{M}$, (b) $10^{-5} \mathrm{M}$, (c) $10^{-6} \mathrm{M}$, and (d) $10^{-7} \mathrm{M} \mathrm{Cd}$ in $0.01 \mathrm{M}$ $\mathrm{NaCl}$ background electrolyte solution, and (e) the black suspensions after filtration with 0.2 $\mu \mathrm{m}$ filters indicating incomplete filtration when $\mathrm{Cd}$ was reacted with $\mathrm{FeS}$ in $0.01 \mathrm{M} \mathrm{NaCl}$ background electrolyte solution. Cd_ultra and Fe_ultra indicates dissolved $\mathrm{Cd}$ and Fe concentration in solution samples filtered using $0.015 \mu \mathrm{m}$ filters, respectively.

Figure S3. X-ray diffraction patterns of Cd reacted with FeS suspensions at different $\mathrm{pH}$ and electrolyte concentration.

Figure S4. Spatial elemental distribution maps were collected using characteristic X-rays by STEM (scanning transmission electron microscopy) EDS (energy-dispersive X-ray spectroscopy). The right part of the bulky, platy aggregate is high in $\mathrm{Fe}, \mathrm{S}$, and $\mathrm{Cd}$, most likely FeS mixed with CdS. To the left along the edge is Fe-lacking, S-depleted, and Cd-enriched, indicating $\mathrm{Cd}^{0}$. The prismatic parts in the center are also $\mathrm{Cd}^{0}$.

Figure S5. The TEM ((a) and (b)) images of the nanoscale particle aggregates and (c) STEM image corresponding to (a), and spatial distribution of (d) $\mathrm{Cd}$ and (e) S, confirming that the nanoaggregates are $\mathrm{CdS}$.

Figure S6. EXAFS analysis of the model compound

Figure S7. The Fe $K$ edge XAS spectra of the selected Cd-loaded FeS samples, showing transition of mackinawite to ferric (hydr)oxide with increasing $\mathrm{pH}$ and $\mathrm{Cd}$ loading. Inset is the Fe $1 s \rightarrow 3 d$ transition pre-edge centroid positions of $\mathrm{Cd}$ reacted with FeS under different 
conditions, showing distinct Fe(II) oxidation to Fe(III) in the highest Cd loaded sample under the higher $\mathrm{pH}$ condition (7MH: $\mathrm{pH} 7, \mathrm{Cd}$ surface loading $=2.8 \% ; 7 \mathrm{VH}: \mathrm{pH} 7, \mathrm{Cd}$ surface loading $=28 \%$; 9ML: $\mathrm{pH} 9, \mathrm{Cd}$ surface loading $=11 \%$; 9VH: $\mathrm{pH} 9, \mathrm{Cd}$ surface loading $=28 \%$; Mkn: mackinawite without $\mathrm{Cd}$ addition).

Figure S8. Linear combination fit of $\mathrm{Cd}$ reacted with FeS suspension, showing that the spectrum is reproducible using the combination of $\mathrm{CdS}$, simply adsorbed $\mathrm{Cd}(\mathrm{II})$, and $\mathrm{Cd}^{0}$ spectrum. The least squares fitting suggests that the reaction product of Cd reacted with $1 \mathrm{~g} / \mathrm{L} \mathrm{FeS}$ suspension at $\mathrm{pH} 5.6$ and the initial $\mathrm{Cd}$ of $11.8 \mathrm{mM}$ consists of $85 \% \mathrm{CdS}, 9.5 \%$ simple adsorbed $\mathrm{Cd}(\mathrm{II})$, and $5.3 \% \mathrm{Cd}^{0}$. 
Figure S1
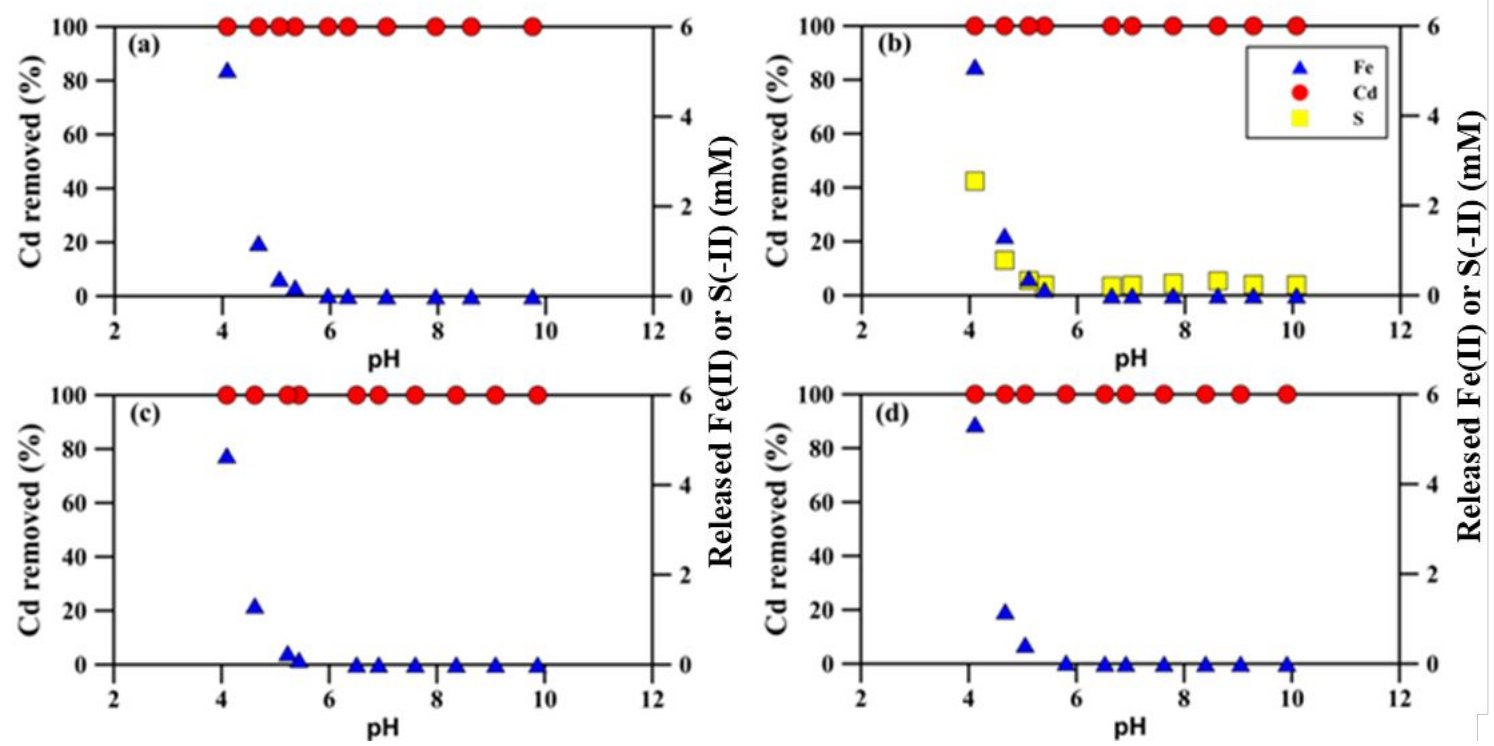
Figure S2
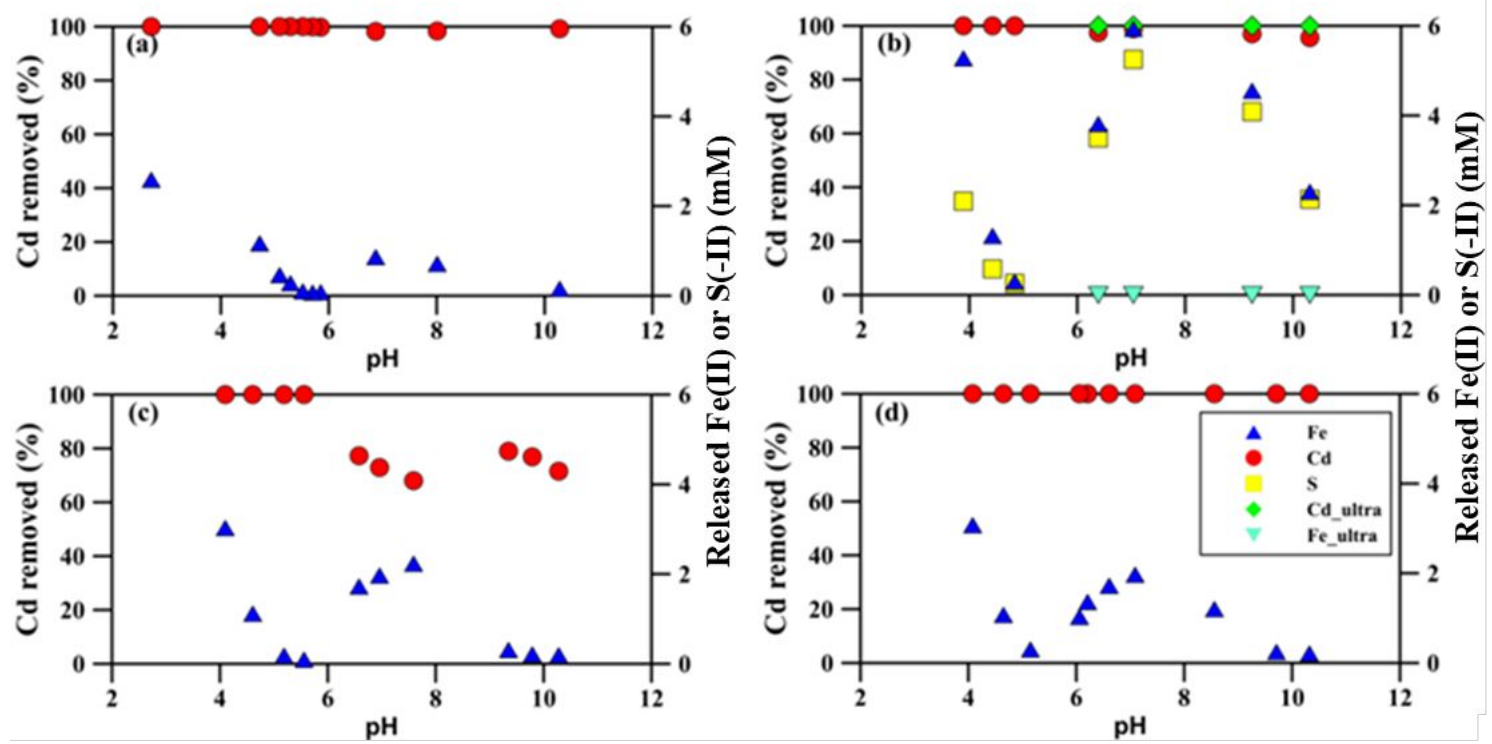

(e)

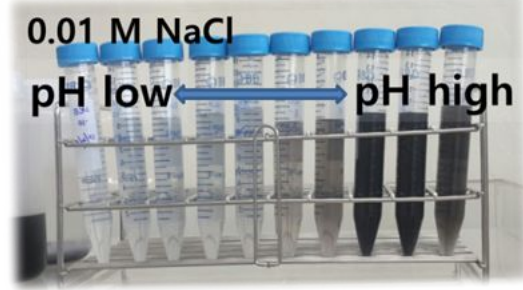


Figure S3

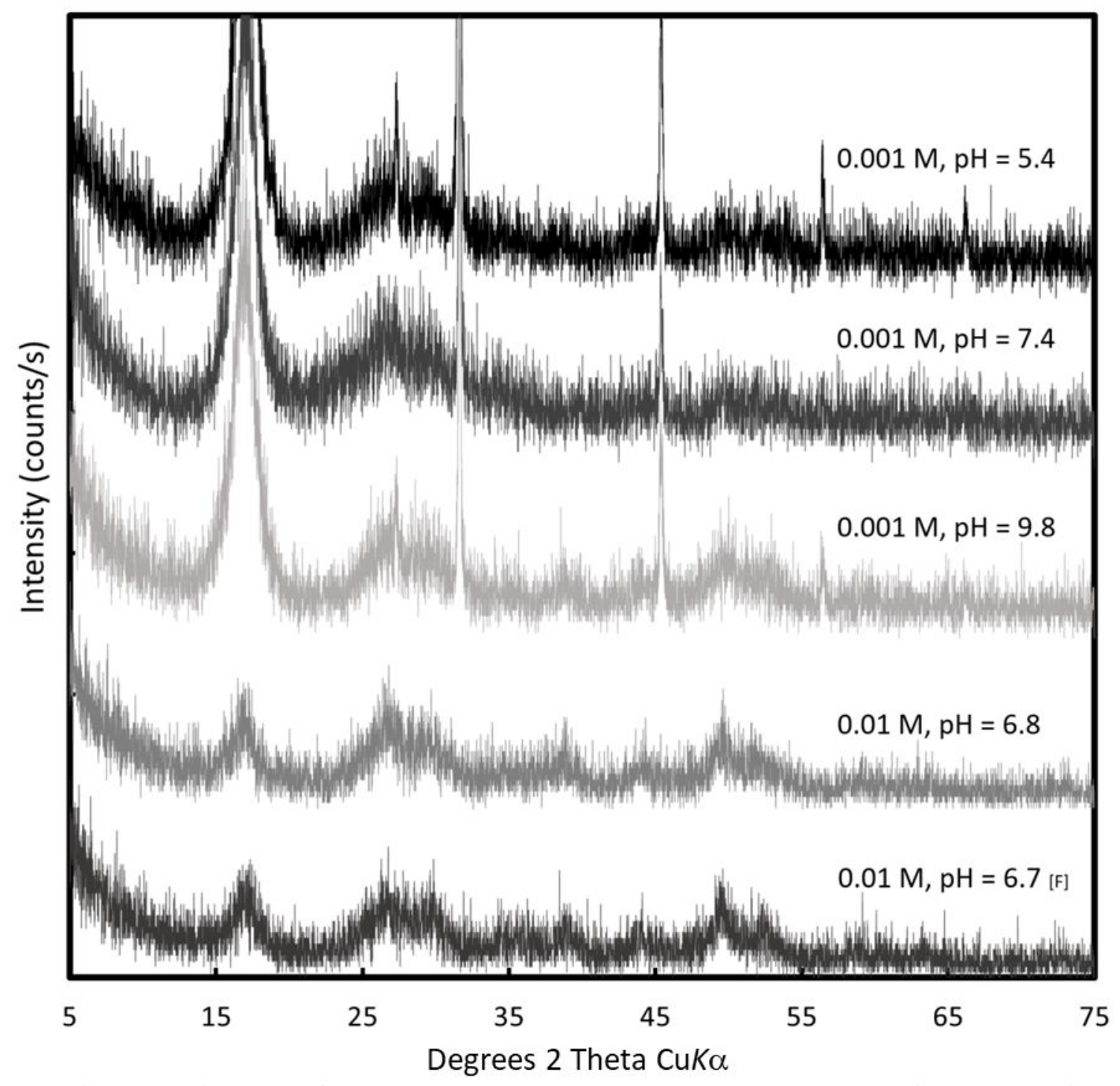

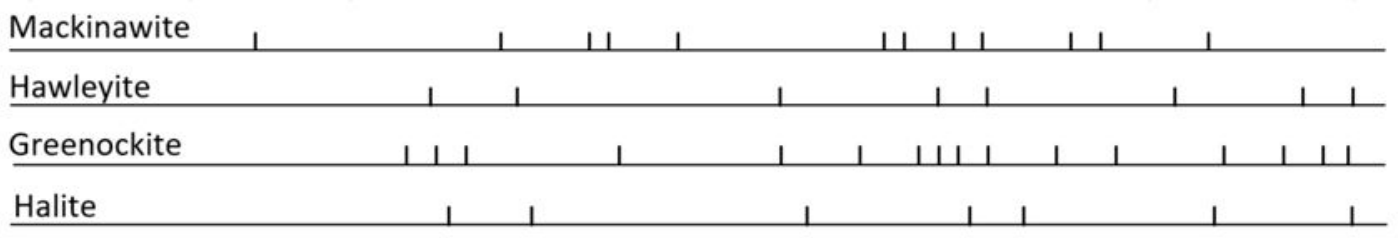


Figure S4

Cd L $\alpha 1$

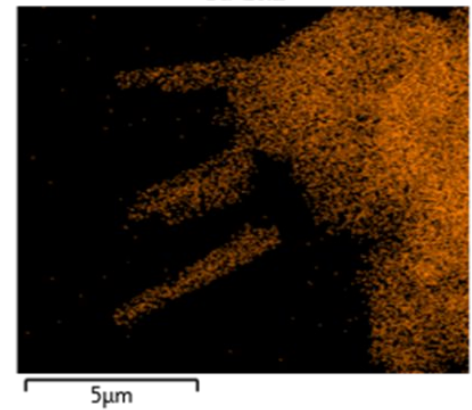

$\mathrm{S} K \alpha 1$

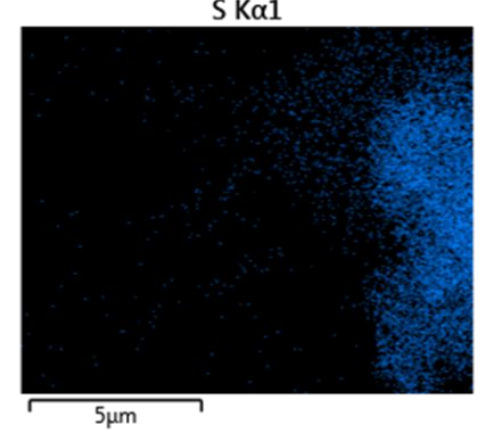

Fe K $\alpha 1$
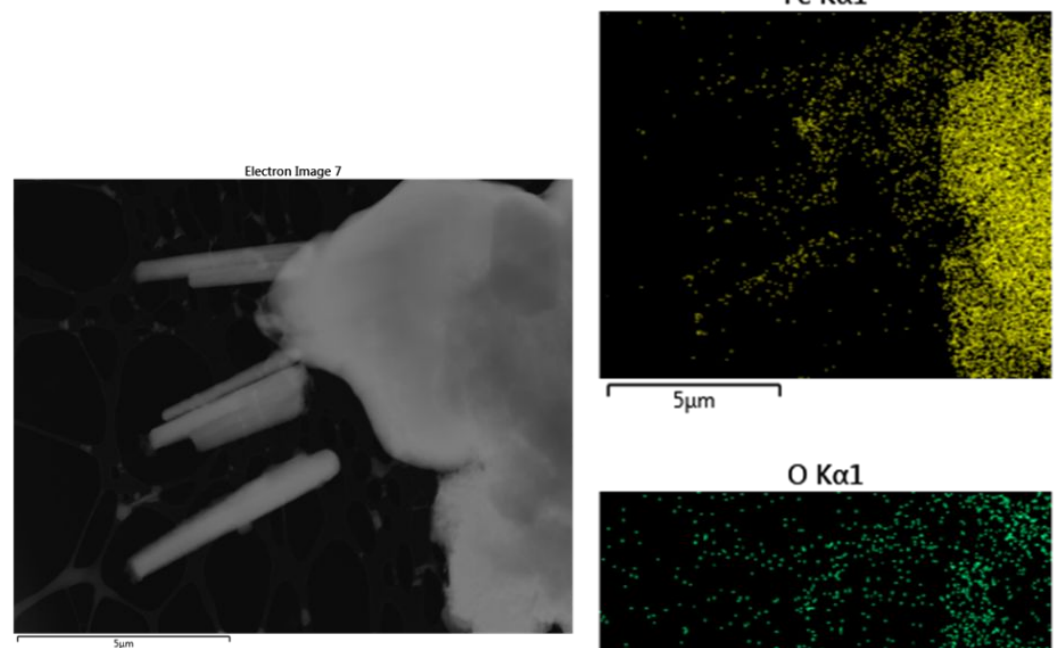

$\mathrm{O} K \alpha 1$

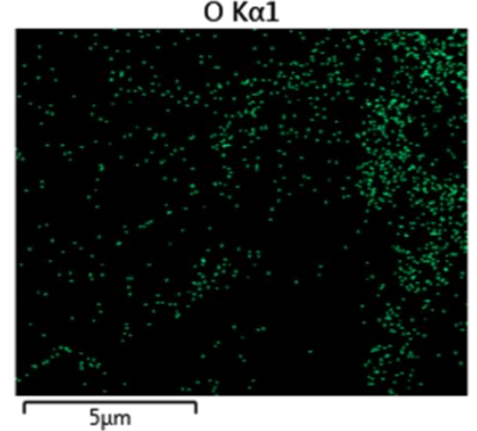


Figure S5
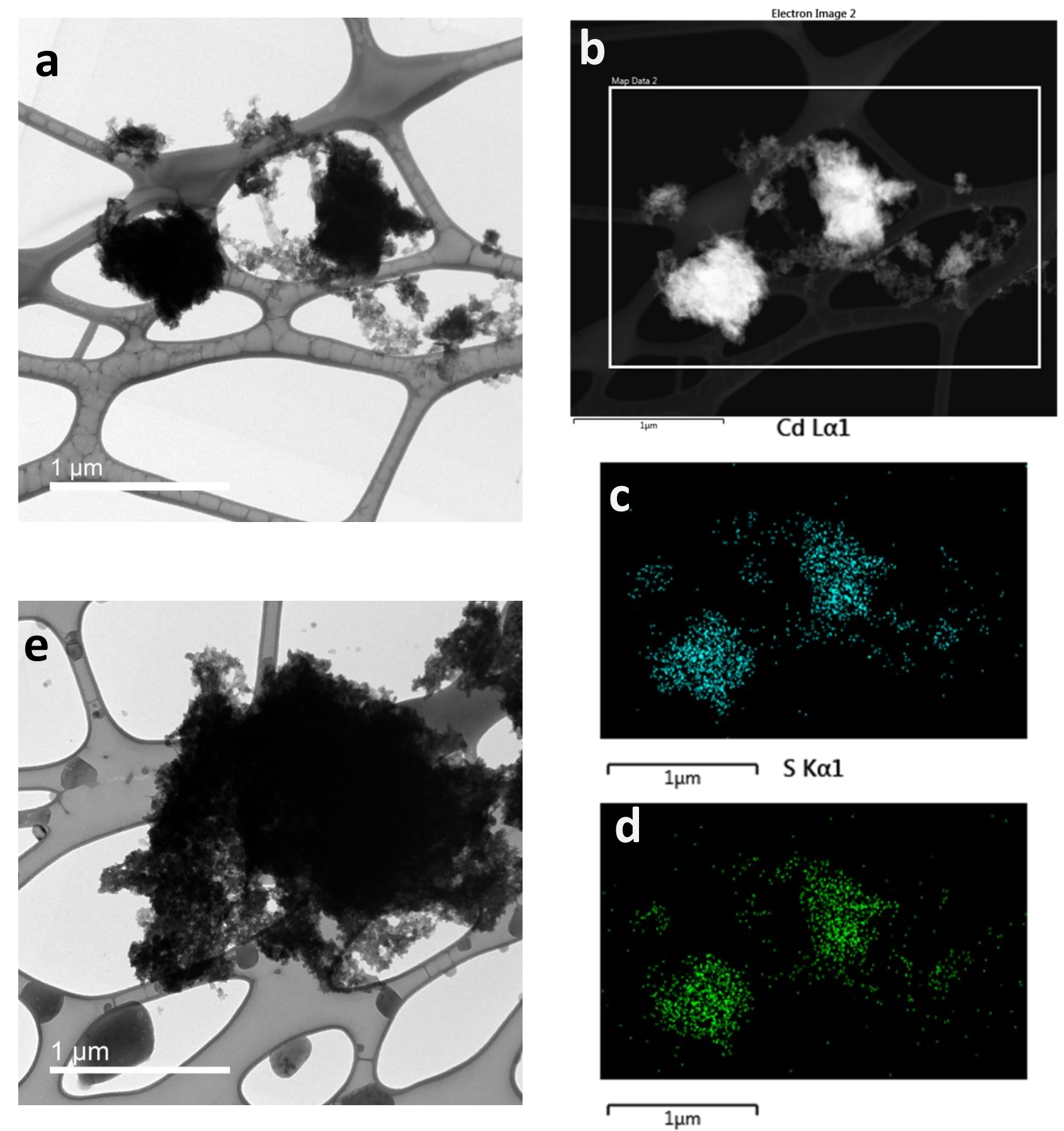
Figure S6
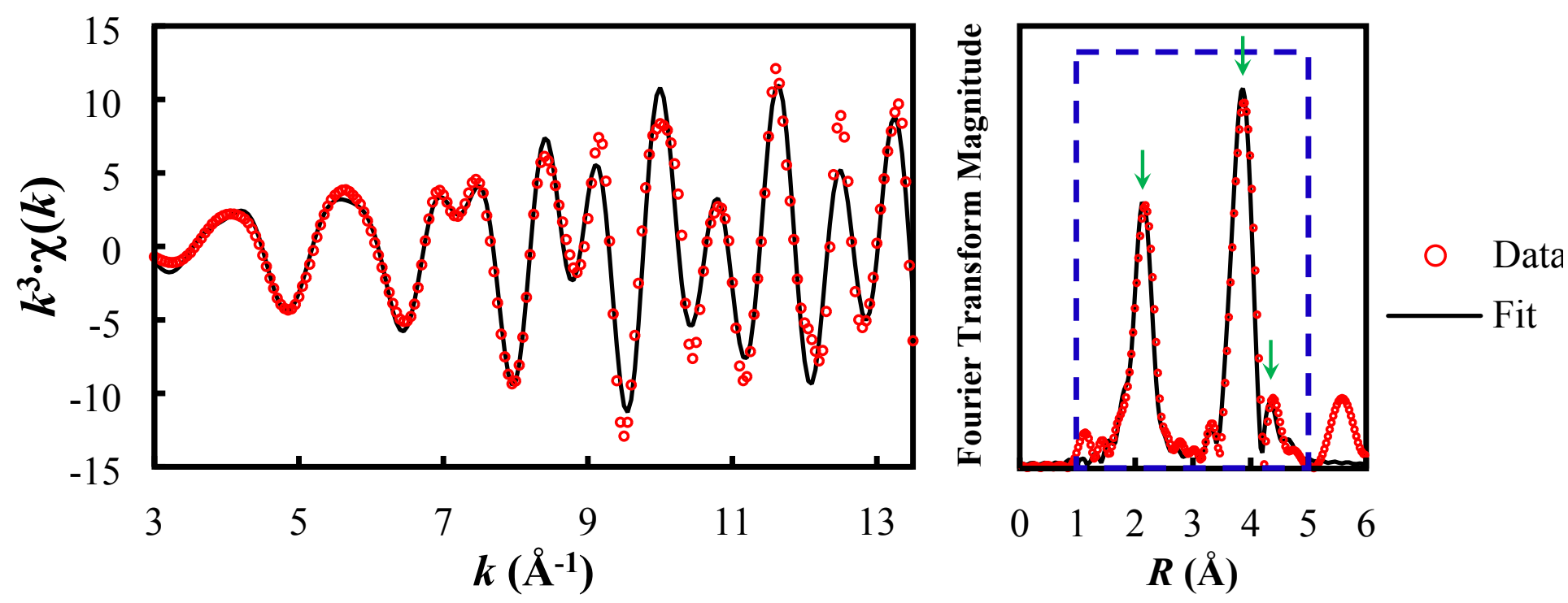
Figure S7

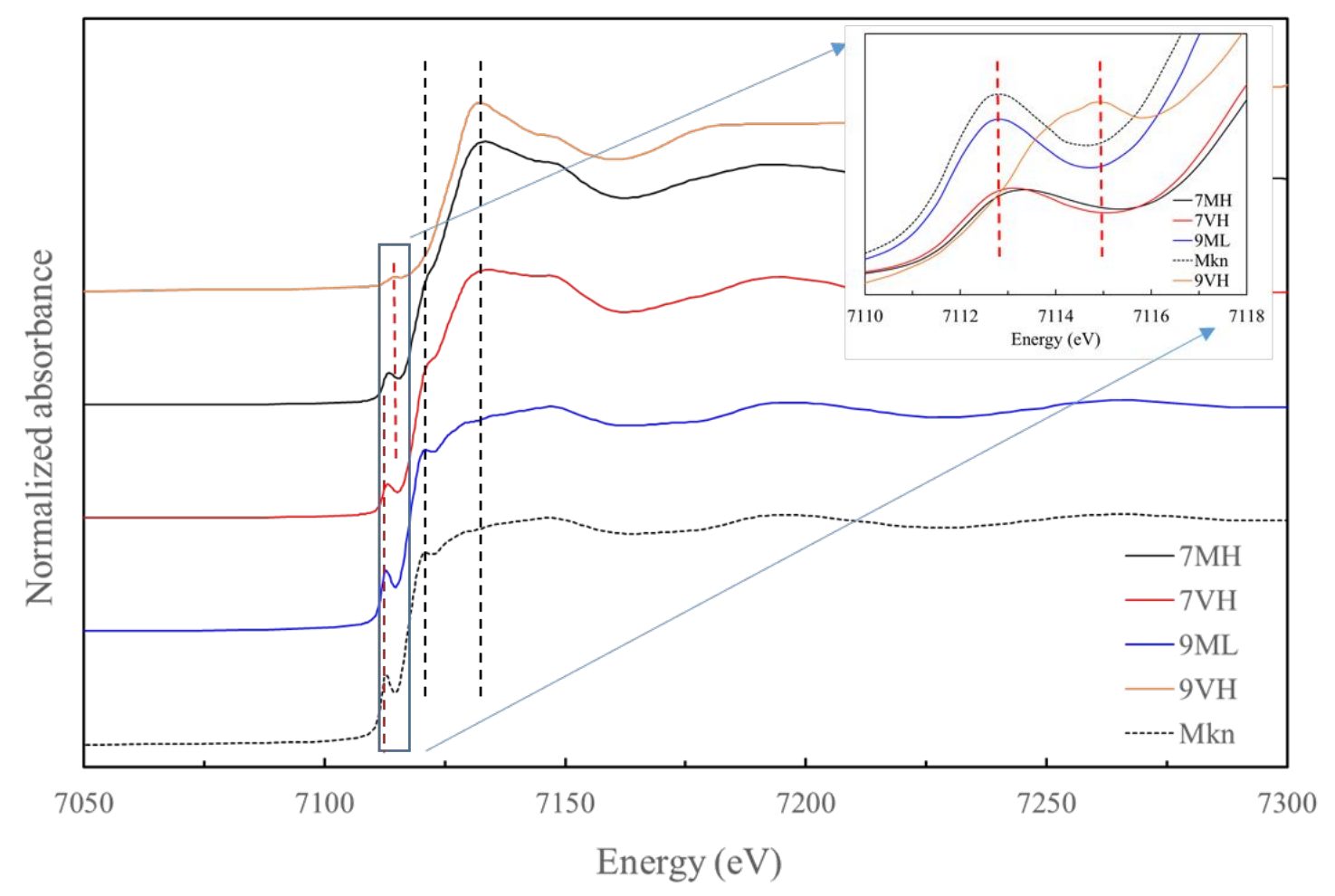


Figure S8

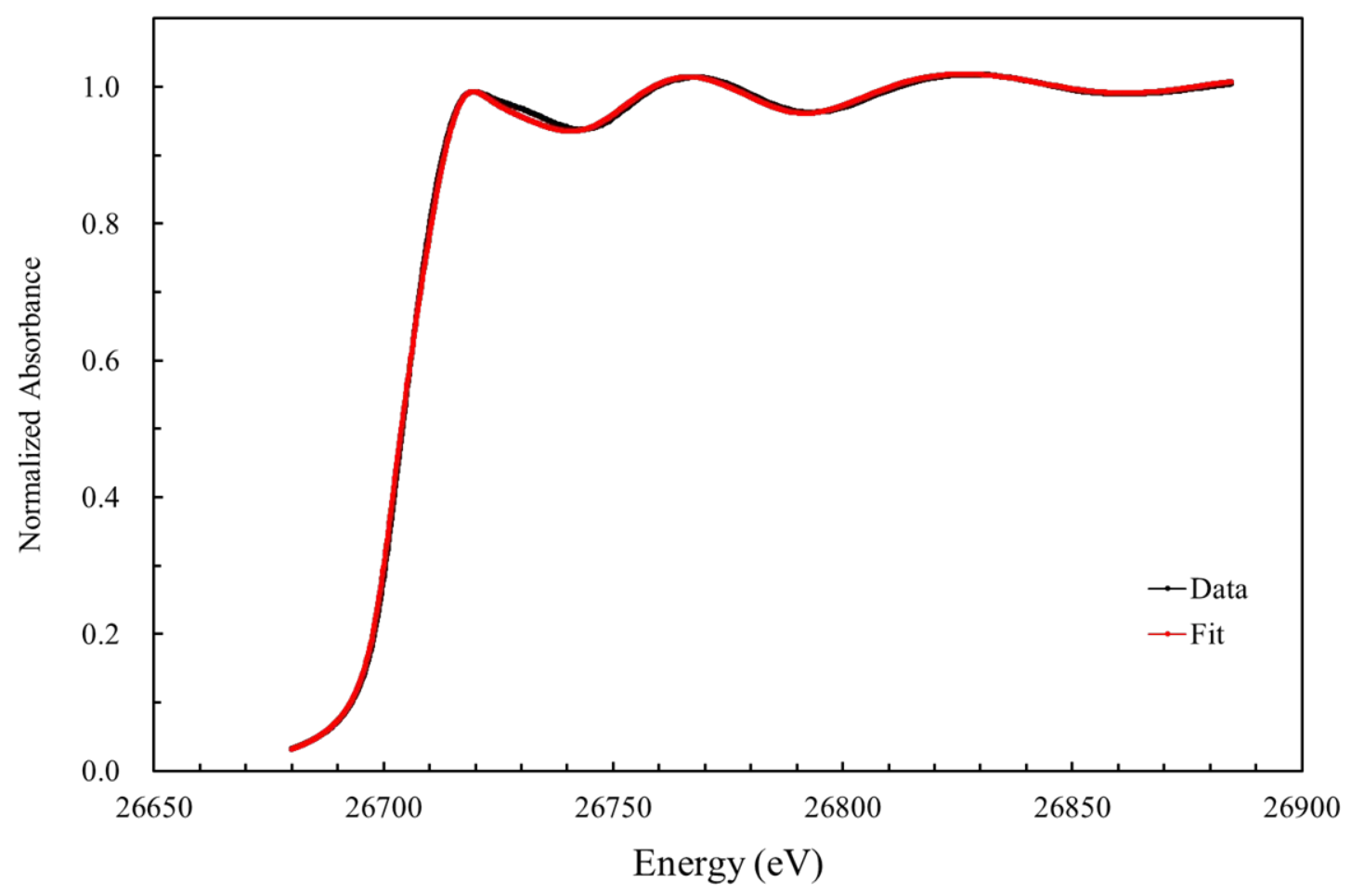

